\title{
Development of a vehicle emission inventory with high temporal-spatial resolution based on NRT traffic data and its impact on air pollution in Beijing - Part 2: Impact of vehicle emission on urban air quality
}

\author{
Jianjun He ${ }^{1}$, Lin Wu${ }^{1}$, Hongjun Mao ${ }^{1}$, Hongli Liu ${ }^{2}$, Boyu Jing ${ }^{1}$, Ye Yu ${ }^{3}$, Peipei Ren ${ }^{1}$, Cheng Feng ${ }^{4}$, and Xuehao Liu \\ ${ }^{1}$ The College of Environmental Science and Engineering, Nankai University, Tianjin, China \\ ${ }^{2}$ Chinese Academy of Meteorological Sciences, China Meteorological Administration, Beijing, China \\ ${ }^{3}$ Cold and Arid Regions Environmental and Engineering Research Institute, Chinese Academy of Sciences, Lanzhou, China \\ ${ }^{4}$ Tianjin Vehicle Emission Control Center, Tianjin, China
}

Correspondence to: Hongjun Mao (hongjun_mao@hotmail.com) and Hongli Liu (liuhongli@cams.cma.gov.cn)

Received: 30 April 2015 - Published in Atmos. Chem. Phys. Discuss.: 14 July 2015

Revised: 28 November 2015 - Accepted: 10 December 2015 - Published: 10 March 2016

\begin{abstract}
A companion paper developed a vehicle emission inventory with high temporal-spatial resolution (HTSVE) with a bottom-up methodology based on local emission factors, complemented with the widely used emission factors of COPERT model and near-real-time (NRT) traffic data on a specific road segment for 2013 in urban Beijing (Jing et al., 2016), which is used to investigate the impact of vehicle pollution on air pollution in this study. Based on the sensitivity analysis method of switching on/off pollutant emissions in the Chinese air quality forecasting model CUACE, a modelling study was carried out to evaluate the contributions of vehicle emission to the air pollution in Beijing's main urban areas in the periods of summer (July) and winter (December) 2013. Generally, the CUACE model had good performance of the concentration simulation of pollutants. The model simulation has been improved by using HTSVE. The vehicle emission contribution (VEC) to ambient pollutant concentrations not only changes with seasons but also changes with time. The mean VEC, affected by regional pollutant transports significantly, is 55.4 and $48.5 \%$ for $\mathrm{NO}_{2}$ and 5.4 and $10.5 \%$ for $\mathrm{PM}_{2.5}$ in July and December 2013 respectively. Regardless of regional transports, relative vehicle emission contribution (RVEC) to $\mathrm{NO}_{2}$ is 59.2 and $57.8 \%$ in July and December 2013, while it is 8.7 and $13.9 \%$ for $\mathrm{PM}_{2.5}$. The RVEC to $\mathrm{PM}_{2.5}$ is lower than the $\mathrm{PM}_{2.5}$ contribution rate for vehicle emission in total emission, which may be due to
\end{abstract}

dry deposition of $\mathrm{PM}_{2.5}$ from vehicle emission in the nearsurface layer occuring more easily than from elevated source emission.

\section{Introduction}

In recent years, the serious atmospheric environment problems in China attract special attention from governments, the public, and researchers. Due to the control of coal combustion, the type of air pollution is changing from smoke to vehicle exhaust and mixed sources; additionally, secondary aerosols and regional transport play an important role in severe haze episodes (Zhang et al., 2006; Huang et al., 2014), which makes it more difficult to control air pollution. Air pollution caused by traffic emission has become the main concern of pollution control, especially in metropolitan cities. Direct emission pollutants from road traffic include nitrogen oxides $\left(\mathrm{NO}_{x}\right)$, carbon monoxide $(\mathrm{CO})$, hydrocarbon $(\mathrm{HC})$, particulate matter (PM), and others (Zhou et al., 2005; Song and Xie, 2006). Based on RAINS-ASIA computer model, the direct emissions of sulfur dioxide $\left(\mathrm{SO}_{2}\right)$, nitrogen oxides $\left(\mathrm{NO}_{x}\right)$, and $\mathrm{CO}$ from five sectors including industry, power, domestic, transportation, and biofuels in 1990, 1995, and 2020 were estimated for China by Streets and Waldhoff (2000); the transportation sector contributed in 1990 and 
1995 approximately 1 and $2 \%$ to total $\mathrm{SO}_{2}$ emissions, 9 and $12 \%$ to total $\mathrm{NO}_{x}$ emissions and 14 and $22 \%$ to total $\mathrm{CO}$ emissions respectively. Traffic emission makes a significant contribution to urban air pollution in many cities in China (Qin and Chan, 1993; Fu et al., 2001), while more stringent vehicle emission standards lead to simultaneous reduction of surface ozone $\left(\mathrm{O}_{3}\right)$ and fine particulate matter $\left(\mathrm{PM}_{2.5}\right)$ concentrations (Saikawa et al., 2011).

Beijing, as the capital of China, is one of the most important metropolitan cities in the world, providing living space for a population of over 21 million. The number of vehicles in Beijing increased rapidly during the last decades and hit 5.5 million in 2014, putting an immense pressure on the environment. Research on the impact of vehicle emission in Beijing has been completed from different perspectives. Hao et al. (2001) developed a vehicle emission inventory and investigated the contribution of traffic to atmospheric pollutant concentrations utilizing a Gaussian dispersion model in 1995; vehicle emission contributed 76.8 and $40.2 \%$ to total $\mathrm{CO}$ and $\mathrm{NO}_{x}$ emissions and 76.5 and $68.4 \%$ to ambient $\mathrm{CO}$ and $\mathrm{NO}_{x}$ concentrations. During the Sino-African summit in 2006, the number concentrations of the particles and accumulation modes were seemingly reduced by $20-60 \%$ due to the strict traffic restrictions (Cheng et al., 2008). Zhang et al. (2011) evaluated the effectiveness of air pollution control through traffic restriction measures in August 2007 and discovered road mobile sources were more effective on dust elements than anthropogenic elements of PM. Based on positive matrix factorization (PMF), Liu et al. (2014) investigated the source apportionment of ambient fine particles and found that the vehicle emission was mainly responsible for particles in the size range $10-50 \mathrm{~nm}$ and accounted for $47.9 \%$ of particle number concentration during summertime in 2011. A series of emission control measurements and atmospheric observations during the 2008 Beijing Olympic Games created a valuable case to research the effectiveness of control measures on mitigating air pollution. It was illustrated that the black carbon (BC) concentration after traffic control during the Olympics decreased by $74 \%$ and that diesel trucks were a major contribution to the ambient summertime BC levels (X. Wang et al., 2009). With the $32.3 \%$ traffic flow reduction, numerical simulation revealed that the average reduction rates of $\mathrm{PM}_{10}, \mathrm{CO}$, and $\mathrm{NO}_{2}$ were $28,19.3$, and $12.3 \%$ respectively; however, there was also an increase of $\mathrm{O}_{3}$ at a rate of $25.2 \%$ (Wang and Xie, 2009). Compared with uncontrolled period, on-road air pollutant concentrations during the Olympics air pollution control period, which is concluded from versatile mobile laboratory moving along Beijing's Fourth Ring Road, decreased significantly by up to $54 \%$ for $\mathrm{CO}, 41 \%$ for $\mathrm{NO}_{x}, 70 \%$ for $\mathrm{SO}_{2}$, and $12 \%$ for BC (M. Wang et al., 2009). Hence, there is a certain controversy between previous studies and a significant fluctuation of pollutant concentration contribution in different periods. Further research should be conducted on the effect of traffic emission on Beijing's air quality as a result of air pollution and changes in pollutants' emission characteristics in recent years.

In a companion paper (Jing et al., 2016), a vehicle emission inventory with high temporal-spatial resolution for 2013 in Beijing was established via a bottom-up methodology based on near-real-time (NRT) traffic data. This part (Part 2) utilizes the Chinese Unified Atmospheric Chemistry Environment (CUACE) model to simulate ambient pollutant concentrations and evaluate the contributions of vehicle emission in Beijing main urban areas in periods of summer and winter 2013 based on the sensitivity analysis method of switching on/off pollutant emissions. In Sect. 2, the details of the methods, data sets, and model setup are shown. CUACE model evaluation and the effect of new vehicle emission inventory are presented in Sect. 3. The main conclusions are presented in Sect. 4.

\section{Data and method}

\subsection{Model description}

Developed by the China Meteorological Administration (CMA), the CUACE model is used in this study to simulate air quality in Beijing. CUACE is a unified chemical weather numerical forecasting system which is independent of weather and climate models. It consists of four functional blocks: anthropogenic and natural emissions, atmospheric gaseous chemical mechanisms, atmospheric aerosol chemical mechanisms, and a numerical assimilation system. The gaseous chemical block is based on the Regional Acid Deposition Model (RADM) covering 66 gaseous species (Stockwell et al., 1990; Wang et al., 2015). The aerosol module includes a mixing scheme, clear-sky processes, dry deposition, below-cloud scavenging, and in-cloud processes. Seven aerosol species, i.e. sulfates (SF), soil dust, BC, organic carbon (OC), sea salts, nitrates (NI), and ammonium salts (AM), are considered in aerosol chemical module. The first six aerosol components were divided into 12 bins with a diameter ranging from 0.01 to $40.96 \mu \mathrm{m}$. Based on the mixing assumptions, the ambient size and density of aerosols in a size bin are evaluated. The optical properties of these aerosols are readily computed when the mixing state, composition, and ambient size are determined. The details of sulphur chemistry, cloud chemistry, coagulation, nucleation, condensation, etc. were depicted by Gong et al. (2003). CUACE is online coupled to the fifth-generation Penn State/NCAR mesoscale model (MM5) and Global/Regional Assimilation and PreDiction System (GRAPSE); MM5 is selected to simulate mesoscale meteorological fields in this study. For different research target and application purposes, CUACE is designed with an open interface to allow it to be easily integrated into different time and spatial scale models. A more detailed description can refer to Gong et al. (2009). The performance of CUACE was evaluated by many researchers. Wang et 

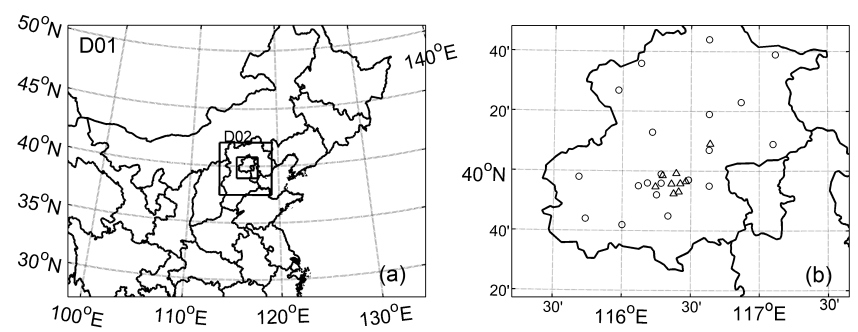

Figure 1. The model simulation domain (a) and observation station distribution (circles represent meteorological station; triangles represent environmental station) in the inner domain (b).

al. (2010) simulated dust weather occurring in April 2006 and indicated that CUACE could predict the outbreak, development, transport, and depletion processes of sand and dust storms accurately over China and the East Asian region. $\mathrm{Li}$ et al. (2014) evaluated air quality prediction by CUACE over Ürümqi and acquired a quite accurate forecasting of air quality levels, especially for $\mathrm{NO}_{2}$ and $\mathrm{PM}_{10}$ levels. Given the good performance in air quality prediction, CUACE has been used for haze forecasting at the National Meteorological Center of CMA and some local environmental protection agencies.

\subsection{Numerical simulation design}

In this study, the MM5-CUACE model is configured to have three nested domains to reduce spurious boundary effects in the inner domain: a horizontal resolution of $27 \mathrm{~km}$ covering North China and the surrounding areas, a resolution of $9 \mathrm{~km}$ covering Jing-Jin-Ji (Beijing, Tianjin and Hebei), and a resolution of $3 \mathrm{~km}$ covering Beijing and surrounding areas (Fig. 1). In the vertical, there are a total of 35 full eta levels extending to the model top at $10 \mathrm{hPa}$, with 16 levels below $2 \mathrm{~km}$.

Two periods: July and December in 2013 are selected for model integration to evaluate different seasonal impacts (summer and winter respectively) of vehicle emission on air quality. The time steps of the MM5 and CUACE models are 15 and 150 s respectively. The driving field provides the initial, lateral, and surface boundary conditions and transmits the weather background information to MM5. However, for large domain or long-term simulations, the largescale weather situation simulated by MM5 may diverge from that of the driving field. The methods to constrain MM5 to the driving field involve frequent re-initialization, analysis nudging, spectral nudging, and scale-selective bias correction (Bowden et al., 2013). A $36 \mathrm{~h}$ re-initialization run is executed to simulate meteorological conditions and air quality, and the former $12 \mathrm{~h}$ simulation is discarded as spin-up time, which is the same as Zhang et al. (2012). The initial and boundary meteorological conditions are from T639 reanalysis data with $30 \times 30 \mathrm{~km}$ spatial resolution and $6 \mathrm{~h}$ temporal resolution supplied by CMA (Xiao et al., 2010). The initial and boundary chemical conditions of the first simulation segment are based on averages from several field studies over the eastern Pacific Ocean (McKeen et al., 2002), which were used as the default profiles in WRF-Chem, and other segment initial and boundary conditions are derived from previous simulation segment. The extra 10-day run (i.e. 21 to 30 June, 21 to 30 November) was conducted to reduce the effect of chemical initial and boundary conditions.

Two real simulations based on default emission of CUACE and the improved emission with a vehicle emission inventory with high temporal-spatial resolution (hereafter referred to as HTSVE) are carried out to evaluate the accuracy of pollutant concentrations simulated by CUACE and analyse the influence of HTSVE on Beijing air quality (hereafter referred to as SIM1 and SIM2). The methods of investigating the contribution rate to ambient pollution level (or source apportionment), based on an air quality numerical model, include source sensitivity simulations using the brute force method (also referred as zero-out method) or the decoupled direct method, air pollution tagged method, and the adjoint method (An et al., 2015; Burr and Zhang, 2011; Zhang et al., 2015). With comprehensible physical and chemical processes, the adjoint method has a significant advantage in source apportionment compared to sensitivity simulations or the tagged method. However, complicated mathematics and a large amount of data processing and programming result in a limited number of available regional-scale air quality adjoint models at present. Recently, An et al. (2015) developed an adjoint of the aerosol module in CUACE. The development of gaseous adjoint module of CUACE is needed for wider applications of source apportionment or source assimilation. The tagged method tracks the contribution of pollutant from specific sources and undergoes explicit atmospheric processes, but it is not able to simulate indirect effects and oxidant-limiting effects. With the ability to simulate indirect effects and relatively simple model runs, source sensitivity analysis is widely used in source attribution. However, significant source variations may result in misunderstandings due to non-linearity and changes in atmospheric background concentrations. In a previous study, the impact of local Beijing emission on air pollution is almost linear in source sensitivity analysis (An et al., 2007). Sensitivity analysis is suitable for investigating the contribution of vehicle emission in Beijing due to limited change of emission in this study. The vehicle emission contribution (VEC) to ambient pollutant concentration is computed based on the sensitivity analysis method of switching vehicle emission on (SIM2) and off (here after refer to SIM3) in Beijing. This method keeps atmospheric background pollution level basically steady, which has a significant effect on the chemical conversion because of relatively limited changes in emission. Meanwhile the effect of vehicle emission on secondary pollution, e.g. secondary aerosols which become important components of PM in Beijing (Huang et al., 2014), was considered. The formula for 
Table 1. Numerical simulation schemes.

\begin{tabular}{ll}
\hline $\begin{array}{l}\text { Numerical } \\
\text { simulation }\end{array}$ & $\begin{array}{l}\text { Emission } \\
\text { source }\end{array}$ \\
\hline SIM1 & Default emission of CUACE \\
SIM2 & Improved emission with Beijing HTSVE \\
SIM3 & Switch off Beijing vehicle emission \\
SIM4 & Switch off Beijing anthropogenic emission \\
\hline
\end{tabular}

VEC is as follows:

$\mathrm{VEC}=\frac{C_{\mathrm{SIM} 2}-C_{\mathrm{SIM} 3}}{C_{\mathrm{SIM} 2}} \times 100 \%$,

where $C$ represents pollutant concentration. In fact, the regional transports of pollutants obviously has an effect on VEC; we calculate relative vehicle emission contribution (RVEC), which does not consider pollutant regional transports, in Eq. (2):

$\mathrm{RVEC}=\frac{C_{\mathrm{SIM} 2}-C_{\mathrm{SIM} 3}}{C_{\mathrm{SIM} 2}-C_{\mathrm{SIM} 4}} \times 100 \%$,

where SIM4 represents the simulation of switching off all emission sources in Beijing. All simulation test schemes are listed in Table 1.

\subsection{Emission inventory}

CUACE has an independent pollution emission module, which contains natural and anthropogenic emissions including many gas and particle matter emissions (Gong et al., 2009). Anthropogenic emissions of $\mathrm{SO}_{2}, \mathrm{NO}_{x}, \mathrm{CO}$, volatile organic compounds, $\mathrm{PM}_{2.5}, \mathrm{PM}_{10}, \mathrm{BC}, \mathrm{OC}$, etc. used in the emission module were developed by CMA based on the INTEX-B inventory, the emissions database for global atmospheric research (EDGAR), and an environmental statistics database. Gridded INTEX-B inventory covers 22 countries and regions in East Asia with a resolution of $0.5^{\circ} \times 0.5^{\circ}$ and is separated into industry emission, power station emission, residential emission, and vehicle emission (Zhang et al., 2009). EDGAR is a joint project of the European Commission Joint Research Centre and the Netherlands Environmental Assessment Agency. The environmental statistics database is supplied by the Environmental Protection Agency. Some old data were corrected or updated according to the variation rate of anthropogenic emissions from environmental statistics database. Finally, the emission inventory was pretreated by SMOKE for detailed temporal and spatial distribution. Hourly emissions were obtained for CUACE model input. The emission inventory is a key factor in air quality numerical simulation. Annual emissions of $\mathrm{CO}, \mathrm{NO}_{x}$, $\mathrm{SO}_{2}$, and $\mathrm{PM}_{2.5}$ in CUACE in Beijing are 3149.5, 173.8, 158.2 , and $79.0 \mathrm{kt}$ respectively. Comparing different research (Table 2) found that there are many uncertainties of inventories, especially for $\mathrm{CO}$ and $\mathrm{NO}_{x}$ emissions, but it is difficult
Table 2. Emission of major anthropogenic species in Beijing (unit: $10^{3} \mathrm{tyr}^{-1}$ ).

\begin{tabular}{lrrrr}
\hline Source & $\mathrm{CO}$ & $\mathrm{NO}_{x}$ & $\mathrm{SO}_{2}$ & $\mathrm{PM}_{2.5}$ \\
\hline CUACE emission & 3149.5 & 173.8 & 158.2 & 79.0 \\
CUACE emission* & 3119.3 & 183.2 & 158.2 & 78.8 \\
An et al. (2007) & 1021.8 & 227.0 & 211.3 & 53.4 \\
Zhang et al. (2009) & 2591.0 & 327.0 & 248.0 & 90.0 \\
Cao et al. (2011) & 1998.0 & 437.0 & 172.0 & 162.0 \\
Wu et al. (2011) & & 236.2 & 172.5 & 67.9 \\
Zhao et al. (2012) & 2580.0 & 309.0 & 187.0 & 90.0 \\
Q. Z. Wu et al. (2014) & 1793.8 & 200.0 & 78.8 & 59.1 \\
\hline
\end{tabular}

* represents CUACE emission with replaced vehicle emission by HTSVE.

Table 3. The rate of major species from vehicle emission in total emission (unit: \%).

\begin{tabular}{lrrrrr}
\hline & $\mathrm{CO}$ & $\mathrm{NO}$ & $\mathrm{NO}_{2}$ & $\mathrm{HC}$ & $\mathrm{PM}_{2.5}$ \\
\hline CUACE $^{\mathrm{a}}$ & 29.8 & 32.1 & 30.4 & 80.0 & 23.4 \\
CUACE $^{\mathrm{b}}$ & 31.1 & 35.5 & 33.6 & 49.0 & 25.3 \\
HTSVE $^{\mathrm{a}}$ & 23.8 & 47.9 & 55.1 & 84.0 & 22.3 \\
HTSVE $^{\mathrm{b}}$ & 21.3 & 46.6 & 53.9 & 55.8 & 20.6 \\
\hline
\end{tabular}

$\mathrm{a}$ and ${ }^{\mathrm{b}}$ represent July and December.

to identify which one is more accurate. With rapid economic development and the adjustment of energy structure, anthropogenic emissions have a significant variation in recent years in North China. However, the database of emission inventory in previous studies (Table 2) is from before 2010, which is the main reason for the differences between CUACE emission and others. For example, the Beijing municipal government has commenced strict traffic restriction since 2008. The number of vehicles in Beijing increased about $8 \%$ in 2013. The change of vehicle emission may be responsible for $\mathrm{NO}_{2}$ emission variation. Except for dates of basic data, the methods of establishing inventory, emission factors, and basic data source would result in significant differences of emission inventory.

This study focuses on vehicle sources and their influence. HTSVE based on NRT traffic data was used to replace the vehicle emission in CUACE emission module to analyse its effects on air quality simulation. The detailed description of vehicle emission with high temporal-spatial resolution and comparison with vehicle emission in CUACE emission module are presented in Part 1 . The contribution of major species from vehicle emission is presented in Table 3 . The vehicle emission of $\mathrm{NO}, \mathrm{NO}_{2}$, and $\mathrm{HC}$ from HTSVE is higher while that of $\mathrm{CO}$ and $\mathrm{PM}_{2.5}$ is lower than from CUACE. 


\subsection{Observational data}

\subsubsection{Meteorological data}

The accuracy of mesoscale meteorological fields simulated by MM5 has a significant effect on air quality simulation, and it should be evaluated with observation data firstly. In this study, the observed near-surface meteorological fields including $2 \mathrm{~m}$ temperature, $2 \mathrm{~m}$ specific humidity, and $10 \mathrm{~m}$ wind speed are obtained from the Meteorological Information Comprehensive Analysis and Process System (MICAPS) of CMA. MICAPS surface data have eight conventional observation times every day (00:00, 03:00, 06:00, 09:00, 12:00, 15:00, 18:00, 21:00 UTC) and 20 meteorological stations located in the study region (Fig. 1a).

\subsubsection{Air quality data}

To evaluate simulated air quality by CUACE, hourly nearsurface average concentrations of $\mathrm{NO}_{2}$ and $\mathrm{PM}_{2.5}$ from nine atmospheric environment monitoring stations in Beijing (shown in Fig. 1b) in simulation periods were acquired from the China National Environment Monitoring Centre. The monitoring stations distributed in the study region could reflect different area pollution levels and capture overall air quality in Beijing.

\section{Results and discussions}

\subsection{Model evaluation and the impact of new vehicle emission inventory}

The accuracy of air quality simulation based on numerical model greatly relates to mesoscale meteorological simulation. Although good performance of MM5 had been obtained in previous studies, our results should be evaluated due to variable performance under different regional, seasonal, and physical parameterization conditions. Based on statistical analysis, the $2 \mathrm{~m}$ temperature root mean square error (RMSE) and correlation coefficient $(R)$ are $3.4 \mathrm{~K}$ and 0.81 in July and $3.8 \mathrm{~K}$ and 0.87 in December. MM5 can capture temporal and spatial variation of near-surface temperature effectively. The $2 \mathrm{~m}$ specific humidity RMSE and $R$ are $2.4 \mathrm{~g} \mathrm{~kg}^{-1}$ and 0.56 in July and $0.9 \mathrm{~g} \mathrm{~kg}^{-1}$ and 0.82 in December, which indicates that basic temporal and spatial variation of nearsurface specific humidity are simulated by MM5. The $10 \mathrm{~m}$ wind speed RMSE and $R$ are $1.4 \mathrm{~m} \mathrm{~s}^{-1}$ and 0.37 in July and $1.7 \mathrm{~m} \mathrm{~s}^{-1}$ and 0.57 in December. The RMSE was $1-4 \mathrm{~K}$ for $2 \mathrm{~m}$ temperature, $1-2 \mathrm{~g} \mathrm{~kg}^{-1}$ for $2 \mathrm{~m}$ specific humidity, and $1-4 \mathrm{~m} \mathrm{~s}^{-1}$ for $10 \mathrm{~m}$ wind speed in most studies (Han et al., 2008; He et al., 2013, 2014; Jiménez-Guerrero et al., 2008; Kioutsioukis et al., 2016; Papalexiou and Moussiopoulos, 2006; Miao et al., 2008). In this study, MM5 presents the essential features of the local circulation over Beijing as seen from the above analysis and its performance observed here
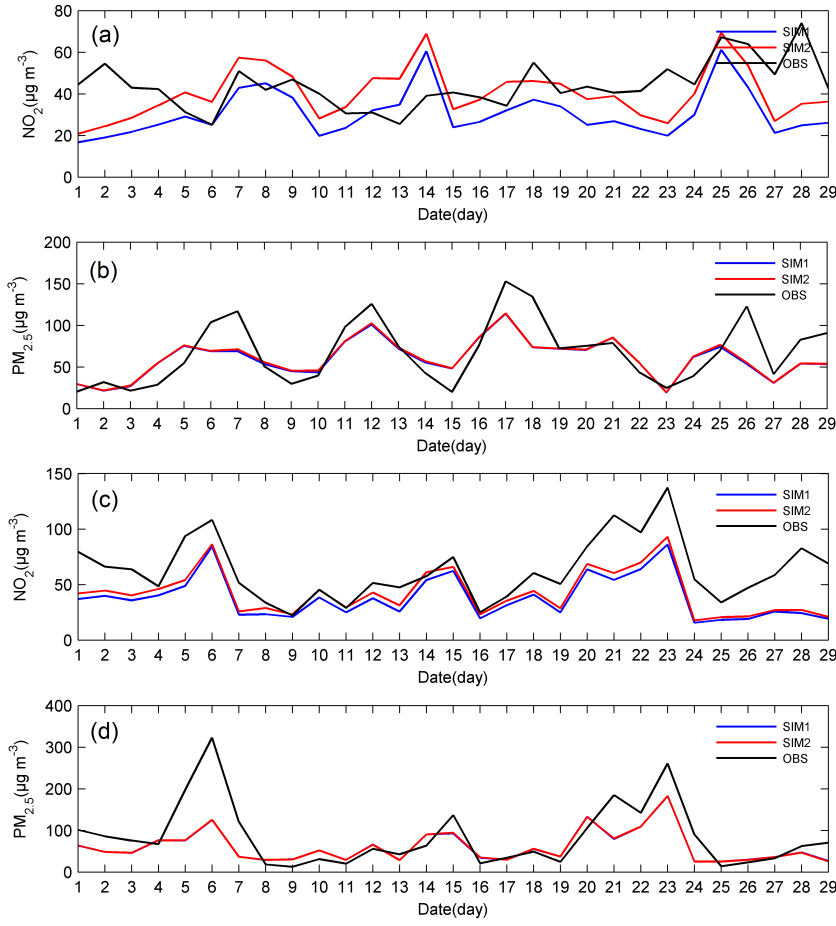

Figure 2. The comparison of site average $\mathrm{NO}_{2}$ and $\mathrm{PM}_{2.5}$ concentrations between SIM1, SIM2, and observation in July $(\mathbf{a}, \mathbf{b})$ and December (c, d) 2013.

is comparable to other studies generally. The details of meteorological evaluation are provided in the Supplement. The statistic parameters are depicted in He et al. (2014).

$\mathrm{NO}_{2}$ and $\mathrm{PM}_{2.5}$ are of major concern as they are susceptible to vehicle emission. Intervals of simulated and observed daily mean near-surface $\mathrm{NO}_{2}$ and $\mathrm{PM}_{2.5}$ concentrations averaged over nine sites during two periods are shown in Fig. 2. CUACE underestimates the $\mathrm{NO}_{2}$ concentration significantly, especially during serious pollution periods. Due to the increasing emission of HTSVE (Table 2), the $\mathrm{NO}_{2}$ concentration from SIM2 increases 31.8 and $11.1 \%$ in July and December respectively, resulting in significant improvement to the previous underestimates. The RMSEs of $\mathrm{NO}_{2}$ daily mean concentration decrease 17.6 and $10.9 \%$ in two periods when HTSVE is used. Temporal correlation coefficients of $\mathrm{NO}_{2}$ daily mean concentrations for SIM1 and SIM2 are 0.80 and 0.79 respectively in December, which indicates CUACE can reproduce $\mathrm{NO}_{2}$ time trends accurately. However, low correlation (0.21 and 0.12 for SIM1 and SIM2 respectively) in July reflects the complexity of air quality numerical simulation. Simulated $\mathrm{PM}_{2.5}$ daily mean concentration is basically consistent with observed value. A minor difference of $\mathrm{PM}_{2.5}$ concentration is observed between SIM1 and SIM2 due to fewer vehicle emission changes (Table 3). Based on temporal correlation analysis, SIM2 improves $\mathrm{PM}_{2.5}$ time trends slightly, with correlation coefficients of 0.75 and 0.77 in SIM1 and 0.76 and 0.78 in SIM2. Compared with SIM1, the 

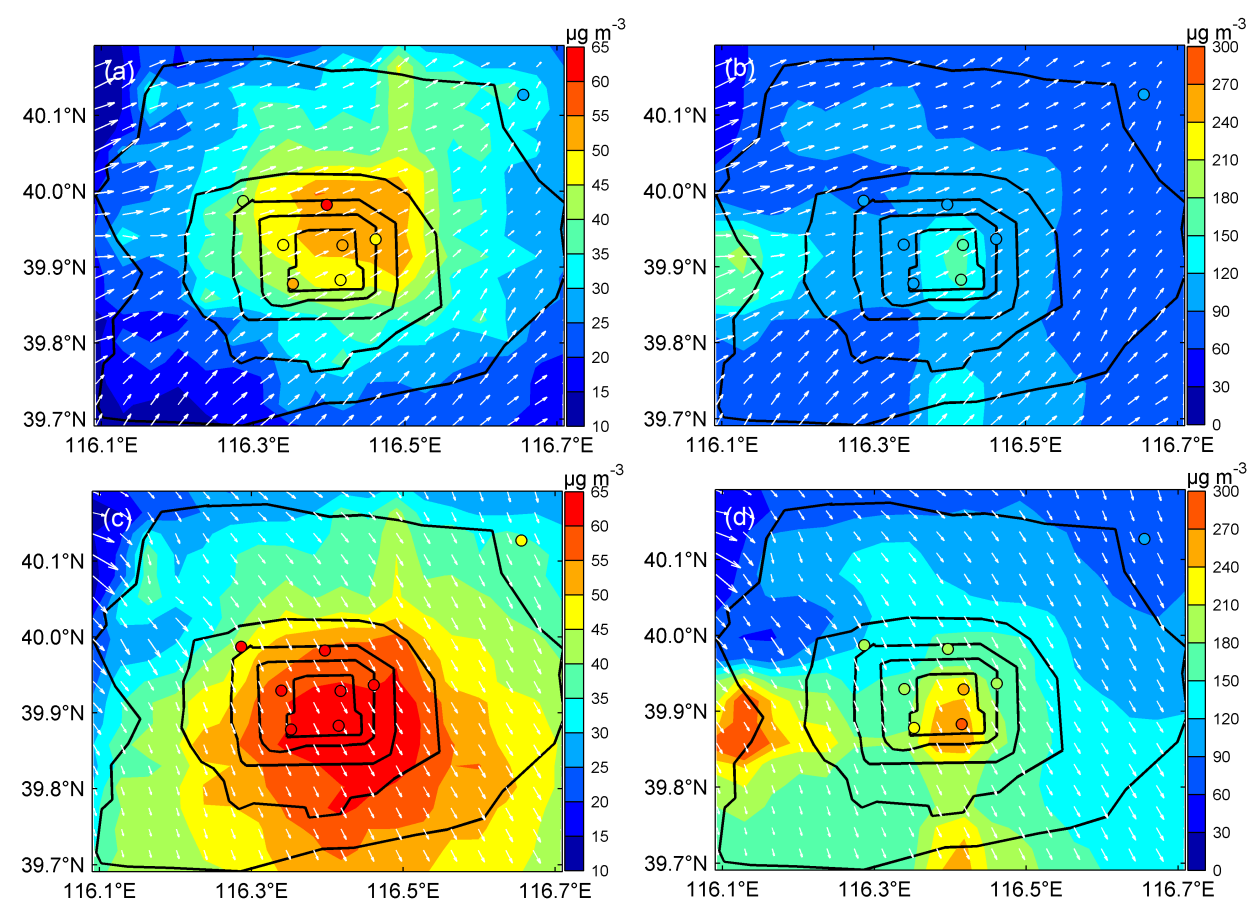

Figure 3. The spatial distribution of near-surface $\mathrm{NO}_{2}$ and $\mathrm{PM}_{2.5}$ mean concentration from SIM2 in July (a, b) and December (c, d) 2013 respectively. Black lines represent the main traffic arteries in Beijing; scatter represents the mean concentrations of sites observation; white arrows represent near-surface mean wind field.

RMSE of $\mathrm{PM}_{2.5}$ daily mean concentration slightly decreased in SIM2. It is obvious that simulated $\mathrm{PM}_{2.5}$ concentration is more accurate than simulated $\mathrm{NO}_{2}$ concentration in July; similar phenomena was found in previous studies (Roustan et al., 2011; Wu et al., 2011). CUACE's ability is evaluated through the comparison of model grid and site station values; however, this method has several uncertainties because local information is involved. It should be noted that the lifetime of ambient $\mathrm{NO}_{2}$ is shorter than that of ambient $\mathrm{PM}_{2.5}$ due to the different chemical processes, and local characteristics are more significant for $\mathrm{NO}_{2}$. The grid average concentration of $\mathrm{NO}_{2}$ simulated by CUACE weakens the subgrid local characteristics and results in poor performance of $\mathrm{NO}_{2}$ simulation compared with $\mathrm{PM}_{2.5}$. The uncertainty of the emission inventory increases with the spatial resolution of the numerical model. Although vehicle emission was replaced with HTSVE, the uncertainty of emission inventories of other sectors in Beijing and all emissions in surrounding areas is still an important reason for the bias of pollutant concentrations. Seasonal differences in CUACE performance are found in this study, with accurate simulation in winter, and this may relate to meteorological conditions, especially wind field bias as mentioned above. The uncertainty of the photochemical reaction, which is more significant in summer, might result in a large bias compared to the performance of $\mathrm{NO}_{2}$ in winter. Overall, the performance of CUACE is comparable with other studies in Beijing (Gao et al., 2011; Wu et al., 2011). Because SIM2 had a better performance, it is used as a baseline scenario in the flowing analysis.

Spatial distribution of pollutant concentration relates to pollutant emission distribution and meteorological condition. The spatial distribution of pollutant concentration from CUACE is basically consistent with site observations (Fig. 3). The mean wind in urban Beijing is the southwesterly wind in July, and it drives local pollutant transports from the southwest to the northeast. The high $\mathrm{NO}_{2}$ concentration is located in northeastern Beijing, while two regions with high $\mathrm{PM}_{2.5}$ concentration appear in the west and city centre (Fig. 3a and b). The spatial distribution of $\mathrm{NO}_{2}$ is different from that of $\mathrm{PM}_{2.5}$ because of emission sources distribution differences with one high-emission area on the inner Fifth Ring Road for $\mathrm{NO}_{2}$ and two high-emission areas on the west Sixth Ring Road and inner Third Ring Road for $\mathrm{PM}_{2.5}$ (Fig. 4). High concentrations present in high emissions or the downwind. The mean concentrations of $\mathrm{NO}_{2}$ and $\mathrm{PM}_{2.5}$ are 29.8 and $91.3 \mu \mathrm{g} \mathrm{m}^{-3}$ in July. Urban Beijing is dominated by northwesterly wind in December, and pollutant concentration distribution is obviously different from that in July. $\mathrm{NO}_{2}$ concentration is high in southeastern Beijing, and gradually decreases outward (Fig. 3c). High $\mathrm{PM}_{2.5}$ concentration is mostly located in western and southeastern Beijing (Fig. 3d). A significant difference in $\mathrm{NO}_{2}$ distribution between July and December and a slight difference of $\mathrm{PM}_{2.5}$ are found due to the combined effect of wind fields and emission distributions. The mean concentrations of $\mathrm{NO}_{2}$ 
and $\mathrm{PM}_{2.5}$ are 42.8 and $136.4 \mu \mathrm{g} \mathrm{m}^{-3}$ in December respectively.

\subsection{The effect of vehicle emission on urban air quality}

VEC to ambient pollutant concentration is analysed through comparison simulation with and without vehicle emission (SIM2 and SIM3 respectively). Probability density function (PDF) is a good way to describe the total representation. The PDF of instantaneous VEC in two periods is shown in Fig. 5. The maximum frequencies of VECs to $\mathrm{NO}_{2}$ in July and December are 55-60 and 50-55\% respectively. The frequencies of VECs to $\mathrm{NO}_{2}$ from 15 to $60 \%$ in December are larger than in July (Fig. 5a), which indicates that a large contribution presents in summer while a small contribution presents in winter. Based on one-way analysis of variance, the difference in VECs to $\mathrm{NO}_{2}$ in summer and winter is significant. This may relate to seasonal differences of meteorological condition and pollutant emission. In summer, high temperature and strong solar radiation lead to strong atmosphere oxidation ability, and therefore it is easy to convert from $\mathrm{NO}$ to $\mathrm{NO}_{2}$, which results in large contribution to $\mathrm{NO}_{2}$ concentration. Meanwhile, the high rate of $\mathrm{NO}_{2}$ emission from vehicle (Table 3) is another reason for the large contribution to ambient $\mathrm{NO}_{2}$ concentration in summer. The VEC to $\mathrm{PM}_{2.5}$ is considerably lower than that to $\mathrm{NO}_{2}$. The maximum frequencies of VECs to $\mathrm{PM}_{2.5}$ in July and December are 0-5 and 5-10\% respectively. Different from $\mathrm{NO}_{2}$, the mean VEC to $\mathrm{PM}_{2.5}$ in summer is smaller than that in winter, with a significant difference from one-way analysis of variance. Relative humidity in summer is higher than that in winter, and high relative humidity is conductive to gas-particle conversion processes of other emission sources (Yao et al., 2014), which may be one of the reasons for small VECs to $\mathrm{PM}_{2.5}$ in summer. The strong turbulence mixing in summer makes rapidly vertical exchange and transport of pollutant in boundary layer and finally results in small VECs to $\mathrm{PM}_{2.5}$ in summer. Wind field variation is another reason for seasonal change of VECs to $\mathrm{PM}_{2.5}$, which will be investigated in the following part.

As the local transports of pollutants, the VEC in Beijing depends on wind field and spatial distribution of vehicle emission. Wind dependency maps of VECs to $\mathrm{NO}_{2}$ and $\mathrm{PM}_{2.5}$ are shown in Fig. 6. High VECs to $\mathrm{NO}_{2}$ in July appeared in southerly wind with $3-4 \mathrm{~m} \mathrm{~s}^{-1}$ and in northerly wind with 6-7 $\mathrm{m} \mathrm{s}^{-1}$ in December. Due to the difference in lifetime between $\mathrm{NO}_{2}$ and $\mathrm{PM}_{2.5}$, the wind dependency map of $\mathrm{PM}_{2.5}$ is quite different from that of $\mathrm{NO}_{2}$. High VECs to $\mathrm{PM}_{2.5}$ in July and December appeared in northerly wind due to high vehicle emission of particle matter in the northeastern part of the city (Jing et al., 2016). The dominant wind is the southwesterly wind in July and northwest in December (Fig. 3), which bring a small VEC to $\mathrm{PM}_{2.5}$ in summer. Significant regional transport, which is analysed in the next section, is one of the reasons for relatively small VECs to $\mathrm{PM}_{2.5}$ in summer.
Figure 7 shows time series of VECs to $\mathrm{NO}_{2}$ and $\mathrm{PM}_{2.5}$ daily mean concentrations in main urban areas (within the Sixth Ring Road) in two periods. The VEC not only changes with seasons, which is consistent with Cheng et al. (2007), but also changes with time. Time series of regional mean VECs of $49.8-60.0 \%$ to ambient $\mathrm{NO}_{2}$ concentration in July, with a mean contribution rate of $55.4 \%$. In December, regional mean contribution on $\mathrm{NO}_{2}$ concentration decreases to $28.5-57.9 \%$ at different days, with a mean contribution rate of $48.5 \%$. The VEC to ambient $\mathrm{PM}_{2.5}$ concentration is less than 10.3 and $13.6 \%$ at different times, with mean contribution rate of 5.4 and $10.5 \%$ in July and December respectively. The change of VECs to $\mathrm{PM}_{2.5}$ between July and December is most caused by meteorological condition in two periods. With different lift time of $\mathrm{PM}_{2.5}$ and $\mathrm{NO}_{2}$, $\mathrm{PM}_{2.5}$ concentration is more affected by regional transports, while $\mathrm{NO}_{2}$ concentration is more affected by local emissions. Therefore the contribution with time variation for $\mathrm{PM}_{2.5}$ is different from that for $\mathrm{NO}_{2}$. Except for wind field, pollution level is an important factor in VECs. It is obvious that low VECs present in serious pollution, while high VECs present in a low pollution concentration level, especially for $\mathrm{NO}_{2}$ (Fig. 8). The absolute contribution of vehicle emission increases in severe pollution mostly because of adverse dispersion condition. However, pollutant regional transport is enhanced in severe pollution, which results in a negative correlation between VEC and pollution concentration level. The VEC has a significant spatial variation; a previous study found that $\mathrm{PM}_{2.5}$ had a larger contribution from vehicle emission in urban than in suburban (13.0-16.3\% vs. $5.1 \%$ ) (S. W. $\mathrm{Wu}$ et al., 2014). Figure 9 shows the spatial distribution of the mean contribution rate of vehicle emission in two periods. Vehicle emission contributes $26.0-76.4$ and $22.9-66.4 \%$ of $\mathrm{NO}_{2}$ at different regions in July and December. A significant effect of vehicle emission on the ambient $\mathrm{NO}_{2}$ concentration level is found in southeastern and northeastern Beijing. VECs to $\mathrm{PM}_{2.5}$ are 1.2-15.4 and 2.4-24.4\% in July and December. The large contribution appears in the northeast in both summer and winter, which is vastly different from the distribution of $\mathrm{NO}_{2}$ contribution.

As can be seen from Table 4, receptor source apportionment and numerical sensitivity analysis are two main methods to compute the VEC to ambient pollutant concentration; additionally, VEC has significant uncertainties from previous studies. In summary, vehicle emission contributes 4-17 and $22 \%$ to $\mathrm{PM}_{2.5}$ concentrations based on receptor source apportionment and numerical simulation methods and 56-74\% to $\mathrm{NO}_{x}$ concentrations based on the numerical simulation method. The differences of the vehicle emission contribution to $\mathrm{PM}_{2.5}$ with the different methods are relatively large. The uncertainties of VEC are related to sampling or simulation time, location, analysis method, and weather conditions. The results from receptor source apportionment (chemical mass balance, PMF, etc.) only represent the characteristics of receptor point and can be applied to primary pollutants (Cheng 

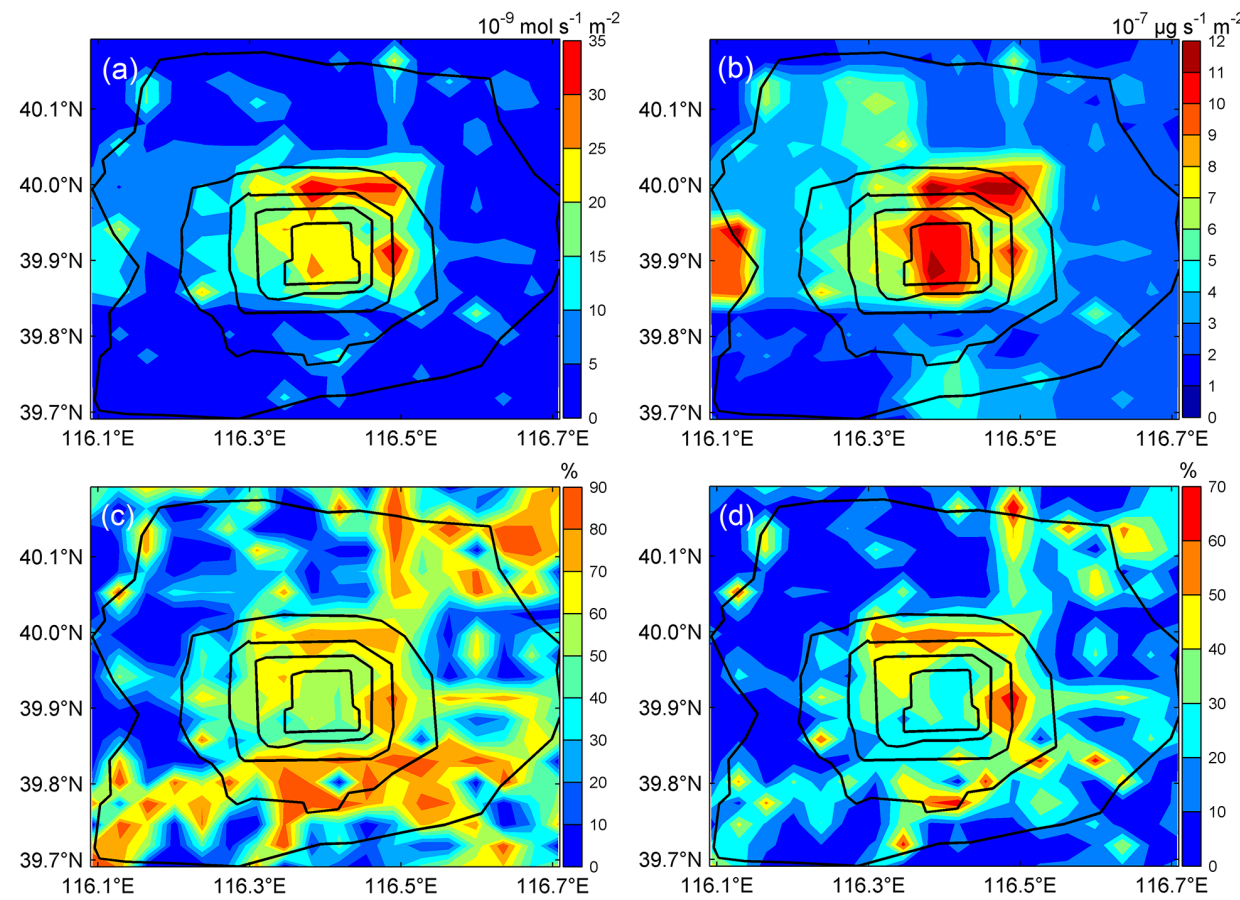

Figure 4. Annual mean emissions and the rate of vehicle emission in total emission for $\mathrm{NO}_{2}(\mathbf{a}, \mathbf{c})$ and $\mathrm{PM}_{2.5}(\mathbf{b}, \mathbf{d})$ respectively. Black lines represent the main traffic arteries in Beijing.

Table 4. The contributions of traffic emission on ambient pollutant concentrations in Beijing.

\begin{tabular}{llll}
\hline Source & Period & Contribution $(\%)$ & Method \\
\hline Hao et al. (2001) & 1995 & $\mathrm{NO}_{x}: 68.4 ; \mathrm{CO}: 76.5$ & Numerical simulation based on ISCST3 \\
Hao et al. (2005) & 1999 & $\mathrm{NO}_{x}: 74 ; \mathrm{PM}_{10}: 14$ & Numerical simulation based on ISCST3 \\
Zheng et al. (2005) & 2000 & $\mathrm{PM}_{2.5}: 6.7$ & Chemical mass balance receptor model (CMB) \\
Song et al. (2006) & 2000 & $\mathrm{PM}_{2.5}: 6.0-10.8$ & PCA/APCS and UNMIX \\
Cheng et al. (2007) & 2002 & $\mathrm{PM}_{10}: 28.7-42.9$ & MM5-ARPS-CMAQ \\
Wang et al. (2008) & $2001-2006$ & $\mathrm{PM}_{2.5}: 5.9 ; \mathrm{PM}_{10}: 8.4$ & Positive matrix factorization (PMF) \\
Zhang et al. (2013) & $2009-2010$ & $\mathrm{PM}_{2.5}: 4$ & PMF \\
Yu et al. (2013) & 2010 & $\mathrm{PM}_{2.5}: 17.1$ & PMF \\
S. W. Wu et al. (2014) & $2010-2011$ & $\mathrm{PM}_{2.5}: 12.0$ & PMF and mixed-effect models \\
Cheng et al. (2013) & 2011 & $\mathrm{PM}_{2.5}: 22.5 \pm 3.5 \mathrm{NO}_{x}: 56-67$ & $\mathrm{MM5-CMAQ} \mathrm{and} \mathrm{source} \mathrm{apportionment} \mathrm{methods}$ \\
Liu et al. (2014) & 2011 & $\mathrm{PM}(\mathrm{NC}): 47.9^{\text {a }}$ & PMF \\
Huang et al. (2014) & 201301 & $\mathrm{PM}_{2.5}: 5.6$ & $\mathrm{CMB}$ and PMF \\
\hline
\end{tabular}
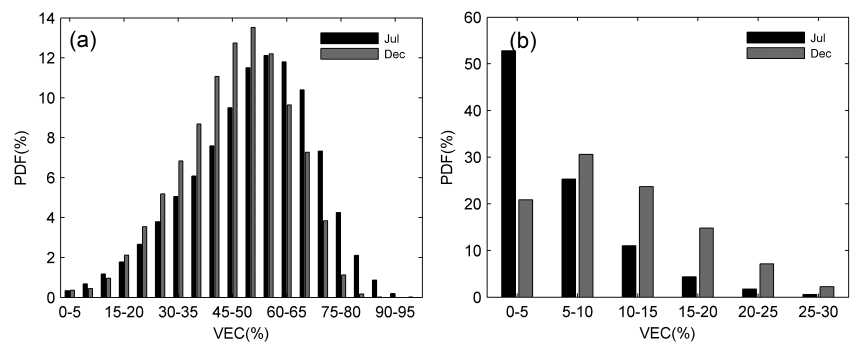

Figure 5. The probability density function (PDF) of instantaneous VECs for $\mathrm{NO}_{2}$ (a) and $\mathrm{PM}_{2.5}$ (b). et al., 2015); however, it is different from numerical sensitivity analysis which normally describes the regional characteristics and applies for primary and secondary pollutants. The uncertainty of emission source in a numerical model may be the main reason for significant differences of VECs in previous numerical studies. Though the simulation in this study is relatively short, our results are still comparable with previous studies. Small differences between our study and previous studies can be attributed to different analyzing periods and methods.

In this study, the rates of $\mathrm{NO}_{2}$ and $\mathrm{PM}_{2.5}$ from vehicle emission account for 55.1 and $22.3 \%$ in July and 53.9 and 

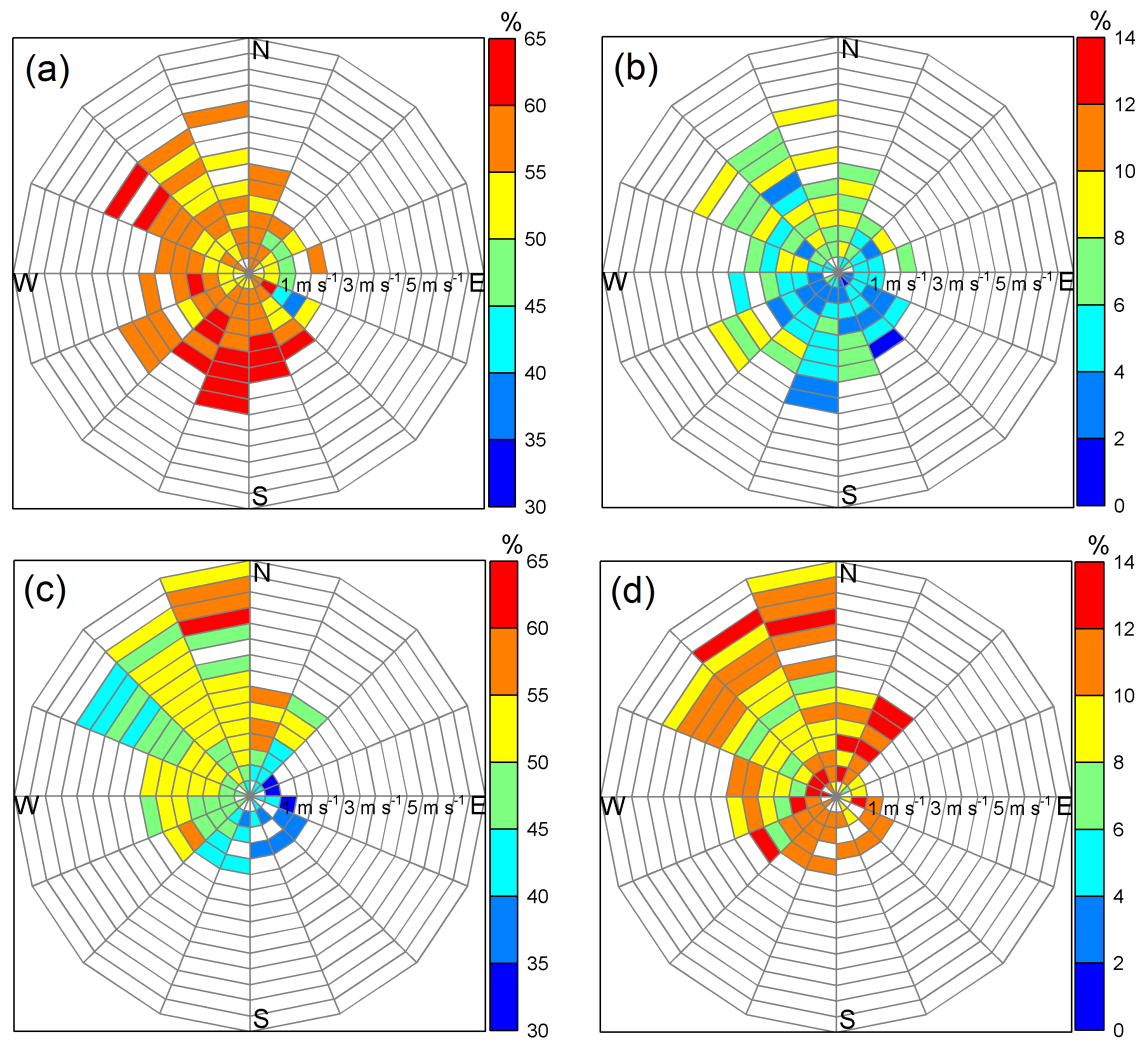

Figure 6. Wind dependency map of VECs to $\mathrm{NO}_{2}$ and $\mathrm{PM}_{2.5}$ in July (a, b) and December (c, d) 2013. Wind speeds are shown from 0 to $7.5 \mathrm{~m} \mathrm{~s}^{-1}$.
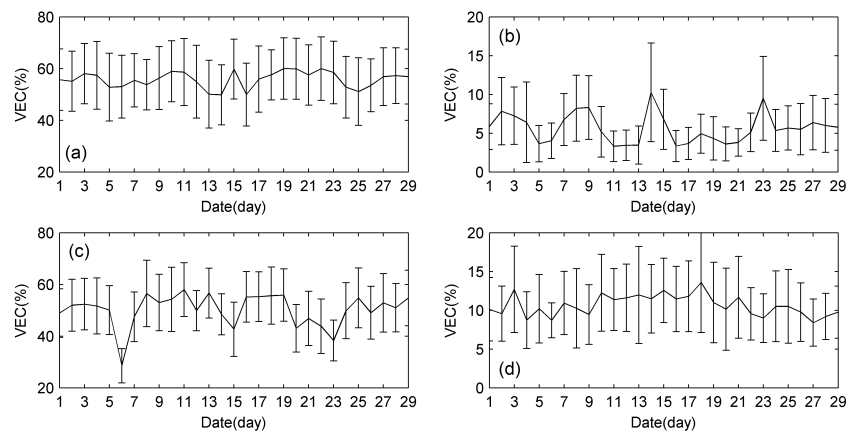

Figure 7. Time series of daily mean and standard deviation of vehicle emission contribution rate on $\mathrm{NO}_{2}$ and $\mathrm{PM}_{2.5}$ concentrations of Beijing main urban areas in July (a, b) and December (c, d) 2013.

$20.6 \%$ in December (Table 3) of total emission. Because of the effect of pollutant regional transports, the contribution rate of vehicle emission on ambient pollutant concentration is lower than the rate of vehicle emission in total emissions. The difference between these two rates became significantly larger with more contribution of outside emission, which implies the importance of weather condition. In order to avoid the effect of weather on analysis results, the relative contribu-
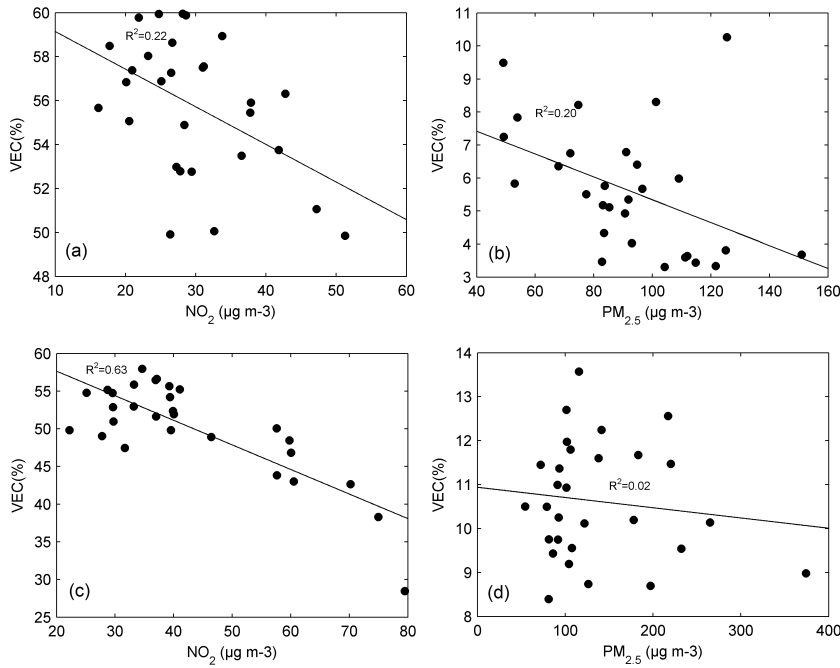

Figure 8. The scatter of daily mean concentration vs. VECs for $\mathrm{NO}_{2}$ and $\mathrm{PM}_{2.5}$ in July $(\mathbf{a}, \mathbf{b})$ and December $(\mathbf{c}, \mathbf{d})$.

tion of vehicle emission on pollutant concentrations is analysed in the following section.

The chemical components of $\mathrm{PM}_{2.5}$ represent the characteristics of emission source and complexity of chemical pro- 
Table 5. The VECs of chemical components in $\mathrm{PM}_{2.5}$ in the urban Beijing region (unit:\%).

\begin{tabular}{lrrrrr}
\hline & $\mathrm{BC}$ & $\mathrm{OC}$ & $\mathrm{NI}\left(\mathrm{NO}_{3}^{-}\right)$ & $\mathrm{SF}\left(\mathrm{SO}_{4}^{2-}\right)$ & $\mathrm{AM}\left(\mathrm{NH}_{4}^{+}\right)$ \\
\hline July & 12.3 & 12.4 & 13.4 & 1.8 & 2.1 \\
December & 24.3 & 25.8 & 15.1 & 7.6 & 4.3 \\
\hline
\end{tabular}

cesses of pollutants in the atmosphere. Based on the sensitivity test, the VECs of BC, OC, and NI are large, while they are relatively small for SF and AM (Table 5). The VECs of $\mathrm{BC}$ and $\mathrm{OC}$ in December are approximately twice of that in July. Seasonal changes for the rates of BC and OC from vehicle emission in total emission are not apparent, which indicates that the seasonal change of VECs is unrelated to vehicle emission. Beijing is controlled by southerly wind, which results in significant regional transport. Additionally, it causes small (large) VECs of BC and OC in summer (winter). Atmospheric chemical processes and dispersion conditions are also the reason for seasonal change of different components VECs. Using MM5-CMAQ model simulation, Cheng et al. (2013) investigated the VEC to the $\mathrm{PM}_{2.5}$ and found the VECs of BC were 32.3 and $30.7 \%$ in summer and winter respectively. Our results are comparable with Cheng et al. (2013) in winter, while they show some difference in summer.

\subsection{Relative contribution of vehicle emission}

Air pollution in Beijing is attributed not only to local emissions but also to regional transports. Using the CMAQ model, An et al. (2007) investigated the contribution to pollutant concentrations in Beijing by using emission switch on/off method; the contribution of non-local emission accounted for $15-53 \%$ of $\mathrm{PM}_{2.5}$. Wu et al. (2011) studied the contribution to air pollution during CARE-Beijing 2006, and local emission in Beijing accounted for $65 \%$ of $\mathrm{SO}_{2}, 75 \%$ of $\mathrm{PM}_{10}$, and $90 \%$ of $\mathrm{NO}_{2}$ concentrations. Pollutant regional transport depends on atmospheric circulation and regional emission characteristics. By comparing pollutant concentrations between SIM2 and SIM4, local emissions in Beijing contribute 93.6 and $62.6 \%$ to $\mathrm{NO}_{2}$ and $\mathrm{PM}_{2.5}$ concentrations in July and 83.8 and $76.1 \%$ to $\mathrm{NO}_{2}$ and $\mathrm{PM}_{2.5}$ concentrations in December, which have a profound effect on RVEC.

Figure 10 depicts the spatial distribution of RVECs to $\mathrm{NO}_{2}$ and $\mathrm{PM}_{2.5}$ in July and December, and a similar distribution is found in two periods. The RVEC to $\mathrm{NO}_{2}$ is large in main southeastern and northeastern urban areas, while small in main western urban areas. Time series of regional mean RVECs to $\mathrm{NO}_{2}$ in main urban areas range from 52.3 to $63.4 \%$ and 49.4 to $61.2 \%$, with means of 59.2 and $57.8 \%$, in July and December respectively. Different from $\mathrm{NO}_{2}$, the RVEC to $\mathrm{PM}_{2.5}$ is large northeast of main urban areas in the two periods. Time series of regional mean RVECs to $\mathrm{PM}_{2.5}$ range from 5.7 to $11.3 \%$ and 9.9 to $16.1 \%$, with means of 8.7 and $13.9 \%$, in July and December respectively. The differences of RVECs to $\mathrm{NO}_{2}$ and $\mathrm{PM}_{2.5}$ in July and December are significant based on one-way analysis of variance. The spatial distribution of RVEC is tremendously affected by vehicle emission, as they are mostly consistent with the rate of vehicle emission in total emission (Fig. 4). As pointed out by Jing et al. (2016), the uncertainty of HTSVE is very small through multiple comparison with statistical data and real-time observation. However, the uncertainty of other sector emissions has a negative influence on the precision of RVECs, which needs more improvement for accurate environmental management. Local circulation also determines the spatial distribution of RVECs. High $\mathrm{PM}_{2.5}$ emission from vehicles is found between north Fourth Ring Road and north Fifth Ring Road (See Part 1, Fig. 9). Controlled by southwesterly wind, $\mathrm{PM}_{2.5}$ from vehicles is easily transferred out of the main urban areas, which results in low RVEC in July. However, the majority of $\mathrm{PM}_{2.5}$ from vehicles stays in the main eastern area of the city controlled by northwesterly wind, which results in high RVEC in December. Based on the zero-out method, Cheng et al. (2013) found the contribution rates to pollutant concentrations were higher than those to the emissions because near-surface emission from vehicles facilitated greater contribution to local pollutant concentrations on the ground level. Regardless of regional transports, the contribution of vehicle emission to ambient $\mathrm{PM}_{2.5}$ concentration is substantial lower than the rate of vehicle emission to total emission in this study. Our finding is seemingly in conflict with Cheng et al. (2013) but may be more reasonable for the following reasons. Different from elevated emission, $\mathrm{PM}_{2.5}$ from vehicle emission in the near-surface layer easily descends to the ground or is absorbed by vegetation, which leads to a low contribution rate to $\mathrm{PM}_{2.5}$ concentration. Secondary aerosol generated by photochemical reaction is different for different sector emissions. The VEC to SF is low in Beijing (Table 5), which indirectly causes low VEC to $\mathrm{PM}_{2.5}$. Furthermore, pollutant regional transport and the background concentration may result in lower VEC to $\mathrm{PM}_{2.5}$ than the rate of emission.

\section{Conclusions}

Air quality simulation has been improved by using HTSVE. In summer (July), high $\mathrm{NO}_{2}$ concentration was located in the northeastern part of city, while two regions with high $\mathrm{PM}_{2.5}$ concentration appeared in the western and centre areas of the city. In winter (December), $\mathrm{NO}_{2}$ concentration was high in the southeast and then gradually decreased outward, while high $\mathrm{PM}_{2.5}$ concentration was mostly located in western and southeastern parts of the city. The VEC in Beijing depends on wind field, spatial distribution of vehicle emission, and air pollution level. High VECs to $\mathrm{NO}_{2}$ in July appeared along with southerly wind and a low pollution concentration level and with northerly wind and a low pollution concentration 

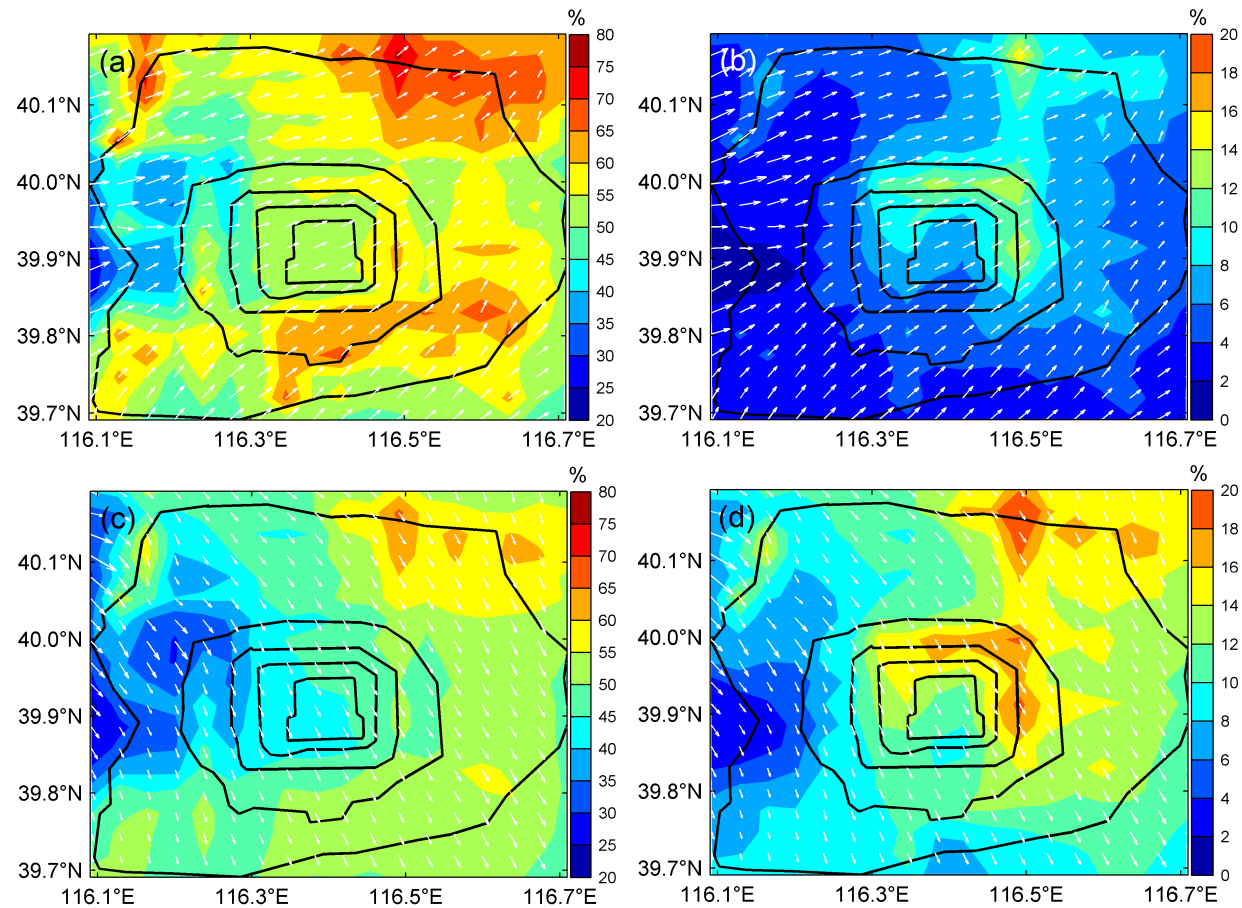

Figure 9. The spatial distribution of mean contribution rate of vehicle emission on $\mathrm{NO}_{2}$ and $\mathrm{PM}_{2.5}$ in July (a, b) and December (c, d) 2013. Black lines represent the main traffic arteries in Beijing; white arrows represent near-surface mean wind field.
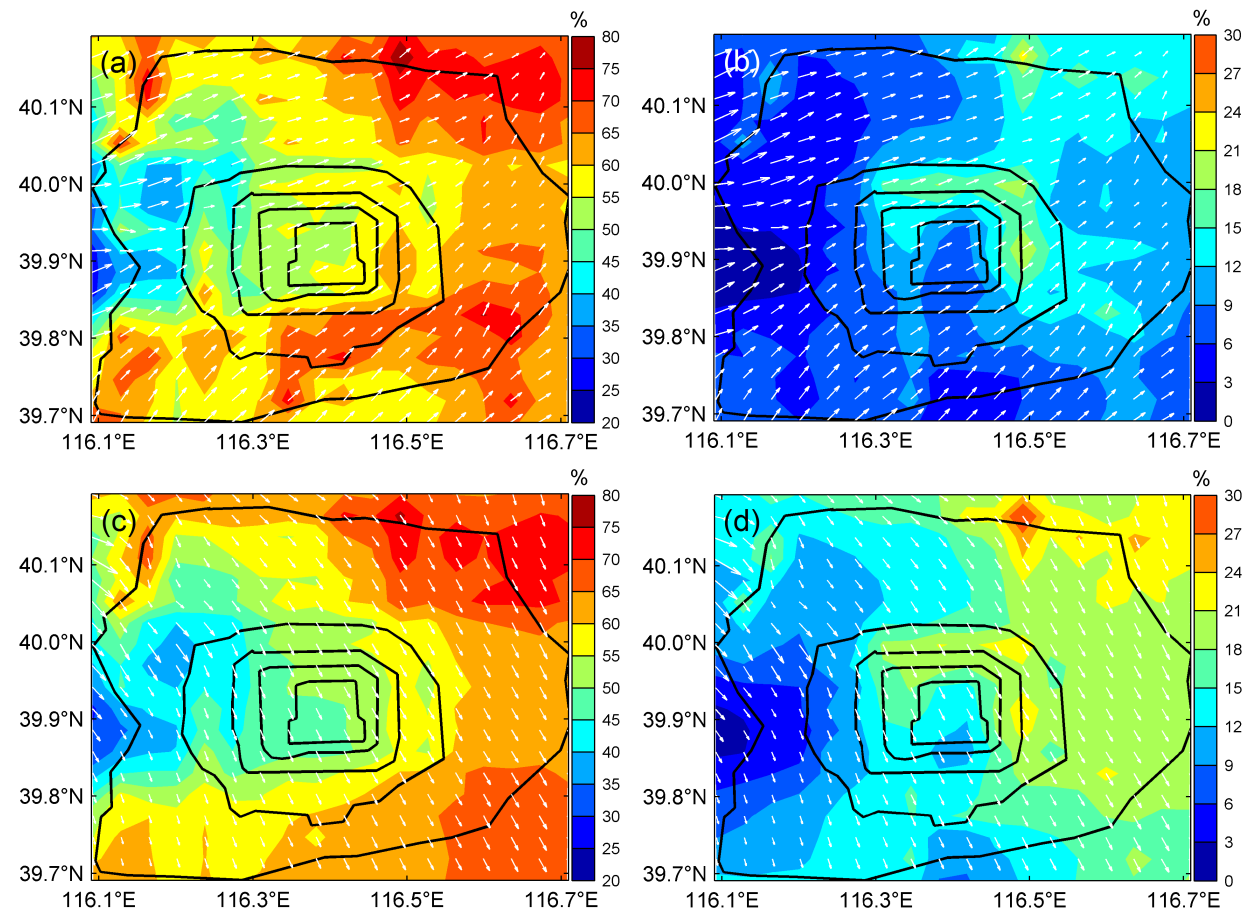

Figure 10. The spatial distribution of vehicle emission contribution in local emission to $\mathrm{NO}_{2}$ and $\mathrm{PM}_{2.5}$ in July (a, b) and December (c, d) 2013. Black lines represent the main traffic arteries in Beijing; white arrows represent near-surface mean wind field. 
level for that in December. High VECs to $\mathrm{PM}_{2.5}$ in July and December appeared along with northerly wind and low pollution concentration level.

Seasonal change of VECs was observed in this study. The mean VECs to $\mathrm{NO}_{2}$ were 55.4 and $48.5 \%$, while the mean VECs to $\mathrm{PM}_{2.5}$ were 5.4 and $10.5 \%$ in July and December respectively. Regional pollutant transport was one of the most important reasons for the small contribution rate for ambient pollutant concentrations compared with the contribution rate for pollutant emission in Beijing. Sensitivity analysis indicated that all local emissions in Beijing contributed 93.6 and $62.6 \%$ to $\mathrm{NO}_{2}$ and $\mathrm{PM}_{2.5}$ concentrations in July and 83.8 and $76.1 \%$ to $\mathrm{NO}_{2}$ and $\mathrm{PM}_{2.5}$ concentrations in December, which had an important effect on RVEC. Regardless of regional transports, the RVECs to $\mathrm{NO}_{2}$ was large in the main southeastern and northeastern urban areas and main northeastern urban areas for $\mathrm{PM}_{2.5}$. The mean RVECs to $\mathrm{NO}_{2}$ were 59.2 and $57.8 \%$, while the mean RVECs to $\mathrm{PM}_{2.5}$ were 8.7 and $13.9 \%$ in July and December respectively. The RVEC to $\mathrm{PM}_{2.5}$ was lower than $\mathrm{PM}_{2.5}$ contribution rate for vehicle emission, which was be due to dry deposition of PM2.5 from vehicle emission in the near-surface layer occuring more easily than from elevated source emission

\section{The Supplement related to this article is available online at doi:10.5194/acp-16-3171-2016-supplement.}

Acknowledgements. This work was supported by China's national 863 program (2012AA063303), the National Science and Technology Infrastructure Program (2014BAC16B03), and the Opening Research Foundation of the Key Laboratory of Land Surface Process and Climate Change in Cold and Arid Regions, Chinese Academy of Sciences (LPCC201405).

Edited by: S. Gong

\section{References}

An, X., Zhu, T., Wang, Z., Li, C., and Wang, Y.: A modeling analysis of a heavy air pollution episode occurred in Beijing, Atmos. Chem. Phys., 7, 3103-3114, doi:10.5194/acp-7-3103-2007, 2007.

An, X. Q., Zhai, S. X., Jin, M., Gong, S. L., and Wang, Y.: Tracking influential haze source areas in North China using an adjoint model, GRAPES-CUACE, Geosci. Model Dev. Discuss., 8, 7313-7345, doi:10.5194/gmdd-8-7313-2015, 2015.

Bowden, J. H., Nolte, C. G., and Otte, T. L.: Simulating the impact of the large-scale circulation on the 2-m temperature and precipitation climatology, Clim. Dynam., 40, 1903-1920, doi:10.1007/s00382-012-1440-y, 2013.
Burr, M. and Zhang, Y.: Source apportionment of fine particulate matter over the Eastern U.S. Part I: source sensitivity simulations using CMAQ with the brute force method, Atmos. Pollut. Res., 2, 299-316, 2011.

Cao, G. L., Zhang, X. Y., Gong, S. L., An, X. Q., and Wang, Y. Q.: Emission inventories of primary particles and pollutant gases for China, Chinese Sci. Bull., 56, 781-788, doi:10.1007/s11434011-4373-7, 2011.

Cheng, I., Xu, X., and Zhang, L.: Overview of receptor-based source apportionment studies for speciated atmospheric mercury, Atmos. Chem. Phys., 15, 7877-7895, doi:10.5194/acp-15-78772015, 2015.

Cheng, S. Y., Chen, D. S., Li, J. B., Wang, H. Y., and Guo, X. R.: The assessment of emission-source contributions to air quality by using a coupled MM5-ARPS-CMAQ modeling system: A case study in the Beijing metropolitan region, China, Environ. Modell. Softw., 22, 1601-1616, doi:10.1016/j.envsoft.2006.11.003, 2007.

Cheng, S. Y., Lang, J. L., Zhou, Y., Han, L. H., Wang, G., and Chen, D. S.: A new monitoring-simulation-source apportionment approach for investigating the vehicular emission contribution to the PM2.5 pollution in Beijing, China, Atmos. Environ., 79, 308316, doi:10.1016/j.atmosenv.2013.06.043, 2013.

Cheng, Y. F., Heintzenberg, J., Wehner, B., Wu, Z. J., Su, H., Hu, M., and Mao, J. T.: Traffic restrictions in Beijing during the Sino-African Summit 2006: aerosol size distribution and visibility compared to long-term in situ observations, Atmos. Chem. Phys., 8, 7583-7594, doi:10.5194/acp-8-7583-2008, 2008.

Fu, L. X., Hao, J. M., He, D. Q., and He, K. B.: Assessment of vehicle pollution in China, J. Air. Waste Manage., 51, 658-668, 2001.

Gao, Y., Liu, X., Zhao, C., and Zhang, M.: Emission controls versus meteorological conditions in determining aerosol concentrations in Beijing during the 2008 Olympic Games, Atmos. Chem. Phys., 11, 12437-12451, doi:10.5194/acp-11-12437-2011, 2011.

Gong, S. L., Barrie, L. A., Blanchet, J. P., von Salzen K., Lohmann, U., Lesins, G., Spacek, L., Zhang, L. M., Girard, E., Lin, H., Leaitch, R., Leighton, H., Chylek, P., and Huang, P.: Canadian aerosol module: a size-segregated simulation of atmospheric aerosol processes for climate and air quality models 1 . Model development, J. Geophys. Res., 108, 4007, doi:10.1029/2001JD002002, 2003.

Gong, S. L., Zhang, X. Y., Zhou, C. H., Liu, H. L., An, X. Q., Niu, T., Xue, M., Cao, G. L., and Cheng, Y. L.: Chemical weather forecasting system CUACE and application in China's regional haze forecasting, in: Proceeding of the 26th Annual Meeting of Chinese Meteorological Society, Hangzhou, 2009.

Han, Z. W., Ueda, H., and An, J. L.: Evaluation and intercomparison of meteorological predictions by five MM5-PBL parameterizations in combination with three land-surface models, Atmos. Environ., 42, 233-249, doi:10.1016/j.atmosenv.2007.09.053, 2008.

Hao, J. M., Wu, Y., Fu, L. X., He, K. B., and He, D. Q.: Motor vehicle source contributions to air pollutants in Beijing, Environ. Sci., 22, 1-6, 2001.

Hao, J. M., Wang, L. T., Li, L., Hu, J. N., and Yu, X. C.: Air pollutants contribution and control strategies of energy-use related sources in Beijing, Sci. China Ser. D, 48, 138-146, 2005.

He, J. J., Yu, Y., Liu, N., and Zhao, S. P.: Numerical model-based relationship between meteorological conditions and air quality and 
its implication for urban air quality management, Int. J. Environ. Pollut., 53, 265-286, 2013.

He J. J., Yu, Y., Liu, N., Zhao, S. P., and Chen J. B.: Impact of land surface information on WRF's performance in complex terrain area, Chinese J. Atmos. Sci., 38, 484-494, doi:10.3878/j.issn.1006-9895.2013, 2014.

Huang, R. J., Zhang, Y. L., Bozzetti, C., Ho, K. F., Cao, J. J., Han, Y. M., Daellenbach, K. R., Slowik, J. G., Platt, S. M., Canonaco, F., Zotter P., Wolf, R., Pieber, S. M., Bruns, E. A., Crippa, M., Ciarelli, G., Piazzalunga, A., Schwikowski, M., Abbaszade, G., Schnelle-Kreis, J., Zimmermann, R., An, Z. S., Szidat, S., Baltensperger, U., Haddad, I. E., and Prévôt, A. S. H.: High secondary aerosol contribution to particulate pollution during haze events in China, Nature, 514, 218-222, doi:10.1038/nature13774, 2014.

Jiménez-Guerrero, P., Jorba, O., Baldasano, J. M., and Gassó, S.: The use of a modeling system as a tool for air quality management: annual high-resolution simulation and evaluation, Sci. Total Environ., 390, 323-340, doi:10.1016/j.scitotenv.2007.10.025, 2008.

Jing, B., Wu, L., Mao, H., Gong, S., He, J., Zou, C., Song, G., $\mathrm{Li}, \mathrm{X}$., and $\mathrm{Wu}, \mathrm{Z}$.: Development of a vehicle emission inventory with high temporal-spatial resolution based on NRT traffic data and its impact on air pollution in Beijing - Part 1: Development and evaluation of vehicle emission inventory, 16, 31613170, doi:10.5194/acp-16-3161-2016, 2016.

Kioutsioukis, I., de Meij, A., Jakobs, H., Katragkou, E., Vinuesa, J., and Kazantzidis, A.: High resolution WRF ensemble forecasting for irrigation: Multi-variable evaluation, Atmos. Res., 167, 156174, doi:10.1016/j.atmosres.2015.07.015, 2016.

Li, M., Zhang, Z. Y., Liu, S. J., Yu, X. J., and Ju, C. X.: Verification of CUACE air quality forecast in Urumqi, Desert Oasis Meteorol., 8, 63-68, 2014.

Liu, Z. R., Hu, B., Liu, Q., Sun, Y., and Wang, Y. S.: Source apportionment of urban fine particle number concentration during summertime in Beijing, Atmos. Environ., 96, 359-369, doi:10.1016/j.atmosenv.2014.06.055, 2014.

McKeen, S. A., Wotawa, G., Parrish, D. D., Holloway, J. S., Buhr, M. P., Hubler, G., Fehsenfeld, F. C., and Meagher, J. F.: Ozone production from Canadian wildfires during June and July of 1995, J. Geophys. Res., 107, 4192, doi:10.1029/2001JD000697, 2002.

Miao, S. G., Chen, F., Lemone, M. A., Tewari, M., Li, Q. C., and Wang, Y. C.: An observational and modeling study of characteristics of urban heat island and boundary layer structures in Beijing, J. Appl. Meteorol. Clim., 48, 484-501, doi:10.1175/2008JAMC1909.1, 2008.

Papalexiou, S. and Moussiopoulos, N.: Wind flow and photochemical air pollution in Thessaloniki, Greece. Part II: Statistical evaluation of European Zooming Model's simulation results, Environ. Modell. Softw., 21, 1752-1758, doi:10.1016/j.envsoft.2005.09.004, 2006.

Qin, Y. and Chan, L. Y.: Traffic source emission and street level air pollution in urban areas of Guangzhou, South China (P.R.C.), Atmos. Environ., 27B, 275-282, 1993.

Roustan, Y., Pausader, M., and Seigneur, C.: Estimating the effect of on-road vehicle controls on future air quality in Paris, France. Atmos. Environ., 45, 6828-6836, doi:10.1016/j.atmosenv.2010.10.010, 2011.
Saikawa, E., Kurokawa, J., Takigawa, M., Borken-Kleefeld, J., Mauzerall, D. L., Horowitz, L. W., and Ohara, T.: The impact of China's vehicle emissions on regional air quality in 2000 and 2020: a scenario analysis, Atmos. Chem. Phys., 11, 9465-9484, doi:10.5194/acp-11-9465-2011, 2011.

Stockwell, W. R., Middleton, P., Chang, J. S., and Tang, X.: The second generation regional acid deposition model chemical mechanism for regional quality modeling, J. Geophys. Res., $9516343-$ 16376, 1990.

Song, X. Y. and Xie, S. D.: Development of vehicle emission inventory in China, Environ. Sci., 27, 1041-1045, 2006.

Song, Y., Xie, S. D., Zhang, Y. H., Zeng, L. M., Salmon, L. G., and Zheng, M.: Source apportionment of PM2.5 in Beijing using principal component analysis/absolute principal component scores and UNMIX, Sci. Total. Environ., 372, 278-286, doi:10.1016/j.scitotenv.2006.08.041, 2006.

Streets, D. G. and Waldhoff, S. T.: Present and future emissions of air pollutants in China: $\mathrm{SO} 2, \mathrm{NO}_{x}$, and $\mathrm{CO}$, Atmos. Environ., 34, 363-374, doi:10.1016/S1352-2310(99)00167-3, 2000.

Wang, H., Gong, S. L., Zhang, H. L., Chen, Y., Shen, X. S., Chen, D. H., Xue, J. S., Shen, Y. F., Wu, X. J., and Jin, Z. Y.: A new-generation sand and dust storm forecasting system GRAPES_CUACE/Dust: Model development, verification and numerical simulation, Chinese Sci. Bull., 55, 635-649, 2010.

Wang, H., Xue, M., Zhang, X. Y., Liu, H. L., Zhou, C. H., Tan, S. C., Che, H. Z., Chen, B., and Li, T.: Mesoscale modeling study of the interactions between aerosols and PBL meteorology during a haze episode in Jing-Jin-Ji (China) and its nearby surrounding region - Part 1: Aerosol distributions and meteorological features, Atmos. Chem. Phys., 15, 3257-3275, doi:10.5194/acp-153257-2015, 2015.

Wang, H. L., Zhuang, Y. H., Wang, Y., Sun, Y., Yuan, H., Zhuang, G. S., and Hao, Z. P.: Long-term monitoring and source apportionment of PM2.5/PM10 in Beijing, China, J. Environ. Sci., 20, 1323-1327, doi:10.1016/S1001-0742(08)62228-7, 2008.

Wang, M., Zhu, T., Zheng, J., Zhang, R. Y., Zhang, S. Q., Xie, X. X., Han, Y. Q., and Li, Y.: Use of a mobile laboratory to evaluate changes in on-road air pollutants during the Beijing 2008 Summer Olympics, Atmos. Chem. Phys., 9, 8247-8263, doi:10.5194/acp-9-8247-2009, 2009.

Wang, T. and Xie, S.: Assessment of traffic-related air pollution in the urban streets before and during the 2008 Beijing Olympic Games traffic control period, Atmos. Environ., 43, 5682-5690, doi:10.1016/j.atmosenv.2009.07.034, 2009.

Wang, X., Westerdahl, D., Chen, L. C., Wu, Y., Hao, J. M., Pan, X. C., Guo, X. B., and Zhang, K. M.: Evaluating the air quality impacts of 2008 Beijing Olympic Games: On-read emission factors and black carbon profiles, Atmos. Environ., 43, 4535-4543, doi:10.1016/j.atmosenv.2009.06.054, 2009.

Wu, Q. Z., Wang, Z. F., Gbaguidi, A., Gao, C., Li, L. N., and Wang, W.: A numerical study of contributions to air pollution in Beijing during CAREBeijing-2006, Atmos. Chem. Phys., 11, 59976011, doi:10.5194/acp-11-5997-2011, 2011.

Wu, Q. Z., Xu, W. S., Shi, A. J., Li, Y. T., Zhao, X. J., Wang, Z. F., Li, J. X., and Wang, L. N.: Air quality forecast of $\mathrm{PM}_{10}$ in Beijing with Community Multi-scale Air Quality Modeling (CMAQ) system: emission and improvement, Geosci. Model Dev., 7, 2243-2259, doi:10.5194/gmd-7-2243-2014, 2014. 
Wu, S. W., Deng, F. R., Wei, H. Y., Huang, J., Wang, X., Hao, Y., Zheng, C. J., Qin, Y., Lv, H. B., Shima, M., and Guo, X. B.: Association of cardiopulmonary health effects with source-appointed ambient fine particulate in Beijing, China: a combined analysis from the healthy volunteer natural relocation (HVNR) study, Environ. Sci. Technol., 48, 3438-3448, doi:10.1021/es404778w, 2014.

Xiao, D., Deng, L. T., Chen, J., and Hu, J. K.: Tentative verification and comparison of WRF forecasts driven by data from T213 and T639 models, Torrent, Rain Disast., 29, 20-29, 2010.

Yao, Q., Cai, Z. Y., Han, S. Q., Liu, A. X., and Liu, J. L.: Effects of relative humidity on the aerosol size distribution and visibility in the winter in Tianjin, China Environ. Sci., 34, 596-603, 2014.

Yu, L. D., Wang, G. F., Zhang, R. J., Zhang, L. M., Song, Y., Wu, B. B., Li, X. F., An, K., and Chu, J. H.: Characterization and source apportionment of PM2.5 in an urban environment in Beijing, Aerosol Air Qual. Res., 13, 574-583, doi:10.4209/aaqr.2012.07.0192, 2013.

Zhang, J. P., Zhu, T., Zhang, Q. H., Li, C. C., Shu, H. L., Ying, Y., Dai, Z. P., Wang, X., Liu, X. Y., Liang, A. M., Shen, H. X., and Yi, B. Q.: The impact of circulation patterns on regional transport pathways and air quality over Beijing and its surroundings, Atmos. Chem. Phys., 12, 5031-5053, doi:10.5194/acp-12-50312012, 2012.

Zhang, L., Liu, L. C., Zhao, Y. H., Gong, S. L., Zhang, X. Y., Henze, D., Capps, S., Fu, T., Zhang, Q., Wang, Y. X.: Source attribution of particulate matter pollution over North China with the adjoint method. Environ. Res. Lett., 10, 084011, doi:10.1088/17489326/10/8/084011, 2015.
Zhang, M. G., Pu, Y., Zhang, R., and Han, Z.: Simulation of sulfur transport and transformation in East Asia with a comprehensive chemical transport model, Environ. Modell. Softw., 21, 812-820, 2006.

Zhang, Q., Streets, D. G., Carmichael, G. R., He, K. B., Huo, H., Kannari, A., Klimont, Z., Park, I. S., Reddy, S., Fu, J. S., Chen, D., Duan, L., Lei, Y., Wang, L. T., and Yao, Z. L.: Asian emissions in 2006 for the NASA INTEX-B mission, Atmos. Chem. Phys., 9, 5131-5153, doi:10.5194/acp-9-5131-2009, 2009.

Zhang, R., Jing, J., Tao, J., Hsu, S.-C., Wang, G., Cao, J., Lee, C. S. L., Zhu, L., Chen, Z., Zhao, Y., and Shen, Z.: Chemical characterization and source apportionment of $\mathrm{PM}_{2.5}$ in Beijing: seasonal perspective, Atmos. Chem. Phys., 13, 7053-7074, doi:10.5194/acp-13-7053-2013, 2013.

Zhang, R. J., Shen, Z. X., Zhang, L. M., Zhang, M. G., Wang, X., and Zhang, K.: Element composition of particles during periods with and without traffic restriction in Beijing: the effectiveness of traffic restriction measure, Sci. Online Lett. Atmos., 7, 61-64, doi:10.2151/sola.2011-016, 2011.

Zhao, B., Wang, P., Ma, J. Z., Zhu, S., Pozzer, A., and Li, W.: A high-resolution emission inventory of primary pollutants for the Huabei region, China, Atmos. Chem. Phys., 12, 481-501, doi:10.5194/acp-12-481-2012, 2012.

Zheng, M., Salmon, L. G., Schauer, J. J., Zeng, L. M., Kiang, C. S., Zhang, Y. H., and Cass, G. R.: Seasonal trends in $\mathrm{PM}_{2.5}$ source contributions in Beijing, China, Atmos. Environ., 39, 3967-3976, doi:10.1016/j.atmosenv.2005.03.036, 2005.

Zhou, Y., Fu, L. X., Yang, W. S., and Wang, Y.: Analysis of vehicle emission in Beijing by remote sensing monitoring, Tech. Equip. Environ. Poll. Contr., 6, 91-94, 2005. 